\title{
INFLUENCIA DEL CATOLICISMO EN LA CONSTITUCIÓN GADITANA: ANÁLISIS DEL JURAMENTO Y LA REPRESENTACIÓN ECLESIÁSTICA POR ANDALUCÍA
}

\author{
POR \\ AMELIA SANCHIS VIDAL ${ }^{1}$ \\ Universidad de Córdoba, Facultad de Derecho y CCEE y Empresariales, Área de Derecho Eclesiástico del Estado, \\ grupo de investigación "Democracia, pluralismo y ciudadanía" (PAI SJ-372) \\ Y \\ Ma JosÉ RAMOS Rovi² \\ Universidad de Córdoba, Facultad de Filosofía y Letras, Área de Historia Contemporánea, grupo de investigación \\ "Regulación Social e Instituciones en Andalucía" (PAI HUM-808)
}

\begin{abstract}
RESUMEN
En este artículo analizamos el papel de la Iglesia católica y del clero andaluz a través de las páginas de los Diarios de sesiones de las Cortes gaditanas (1810-14). En la investigación realizada, destacamos cómo la moral católica se confundió con la del Estado a través del obligado juramento, de la declaración de confesionalidad constitucional, y del imaginario social. Resaltamos cómo el peso del catolicismo afectó a la moral de la época y al discurso de los diputados andaluces en sus intervenciones, o en la falta de ellas. Como aportación original destacamos el apéndice prosopográfico de los diputados eclesiásticos por Andalucía.

PALABRAS CLAVE: Iglesia católica; juramento; eclesiásticos.

\section{THE INFLUENCE OF CATHOLICISM IN THE SPANISH CONSTITUTION OF 1812: AN ANALYSIS OF OATH THE ECCLESIASTIC REPRESENTATION FOR ANDALUSIA}

\begin{abstract}
This paper seeks to analyze the role of the Catholic Church and of Andalusian clergy as reflected in the pages of the Journal of the Cadiz Cortes (1810-14). The process by which Catholic doctrine became intertwined with that of the State through the compulsory oath, through the declaration of constitutional confessionality and the social imaginary are especially relevant to this investigation. Our contention is that the burden of Catholicism affected the morals of the time and the discourse of Andalusian members of Parliament in their speeches or in their choice to remain silent. This proposal also offers an original contribution as it is the prosopographic appendix of the ecclesiastic members of Parliament for Andalusia.
\end{abstract}

KEY WORDS: Catholic Church; oath; ecclesiastic.

Cómo CITAR ESTE ARTículo / CitATION: Sanchis Vidal, A.; Ramos Rovi, M. J. 2017. «Influencia del catolicismo en la Constitución gaditana: análisis del juramento y la representación eclesiástica por Andalucía». Hispania Sacra 69, 139: 307-317. doi: 10.3989/ hs.2017.021

Recibido/Received 05-07-2012

Aceptado/Accepted $\quad$ 08-06-2016

\footnotetext{
dh1savia@uco.es / ORCID iD: http://orcid.org/0000-0002-4668-7763

hi1rarom@uco.es / ORCID iD: http://orcid.org/0000-0001-5723-5431
} 


\section{INTRODUCCIÓN}

No hay unanimidad en la mayoría de las investigaciones realizadas sobre las Cortes de Cádiz. En esta investigación consideramos, al igual que otras autoras y autores, que el papel de la Iglesia católica no fue tan monolítico como se ha considerado en muchos de los estudios realizados; existe una compleja alineación del clero que abarca desde el catolicismo más ultramontano hasta la adhesión de algunos a las ideas liberales. Ese amplio espectro lo hemos percibido mejor siguiendo el rastro de cómo se celebraron los juramentos y cómo fueron sus intervenciones en las sesiones parlamentarias.

De otro lado, la extensa bibliografía sobre la Constitución de 1812 hace difícil elaborar un "estado del arte" en esta investigación. Por cuestiones de espacio no nos detendremos en el asunto, pero no podemos dejar de mencionar que son muchos y variados los excelentes trabajos realizados desde el Derecho y la Historia. ${ }^{3}$

Durante la Guerra de la Independencia, Andalucía fue una de las regiones españolas que sufrió menor número de batallas y, quizá por ello, fue uno de los escenarios de mayor renombre durante el conflicto: proclamación de la Junta Suprema de Sevilla, batalla de Bailén, y la decisiva celebración de las Cortes de Cádiz, que se convirtió en el principio del fin del Antiguo Régimen. Durante aquellos años, en Cádiz, las Cortes estuvieron aisladas del resto del país pergeñando un tránsito que modernizase el Estado español. ${ }^{4}$

Tomás y Valiente se preguntó en su celebérrimo artículo sobre el Constitucionalismo español: «¿se sintió, se supo integrado en la Constitución el pueblo?». ${ }^{5}$ Nosotras consideramos que sí, incluso más de lo que las leyes

3 Valga como muestra, sin ánimo de ser exhaustivas, las siguientes referencias: Alonso Romero, M. P. 2008. Orden procesal y garantías entre Antiguo Régimen y Constitucionalismo gaditano. Madrid; Álvarez Cuartero, I. y Sánchez Gómez, J. (eds.) 2007. Visiones y revisiones de la Independencia Americana. La independencia de América. La Constitución de Cádiz y las Constituciones iberoamericanas. Salamanca; Chust, M. (coord.) 2006. Doceañismos, constituciones e independencias. La Constitución de 1812 y América. Madrid; Clavero, B., Portillo Valdés, J. M. y Lorente, M. 2004. Pueblos, nación, constitución (En torno a 1812).Vitoria-Gasteiz; Garriga, C. y Lorente, M. 2007. Cádiz, 1812. La Constitución jurisdiccional. Madrid; Gómez Rivero, R.2010. La sanción real en la Constitución de Cádiz. Cádiz; Portillo Valdés, J. M. 2000. Revolución de Nación. Orígenes de la cultura constitucional en España, 1780-1812. Madrid; Ramos Santana, A. y Romero Ferrer, A. (eds.) 2008. Cambio político y cultura en la España de entresiglos. Cádiz; Reyero, C. 2010. Alegoría, nación y libertad. El Olimpo Constitucional de 1812. Madrid; Segura Ortega, M. 2002. «Los derechos fundamentales en la Constitución de Cádiz de 1812», en Puy Muñoz, F. (coord.). Los derechos en el Constitucionalismo histórico español. 15-43. Santiago de Compostela; Terradillos Basoco, J. M. (coord.) 2008. Marginalidad, cárcel, las otras creencias. Primeros desarrollos jurídicos de la Pepa. Cádiz.

4 «Las teorías del Estado se podrían simplificar entre las que le otorgan calidad de actor en los procesos históricos o las que hacen del Estado el lugar donde se organizan las clases y grupos sociales y dirimen al máximo nivel sus conflictos. Sin eclesiásticos equidistantes optamos por calibrar el despliegue de la actividad estatal no desde criterios exclusivamente funcionales, sino también como agente activo con capacidad autónoma para producir resultados no previstos por las clases y sectores sociales implicados en las instituciones estatales» (Pérez Garzón 2009).

5 Tomás y Valiente 1977: 87. permitieron. Hubo una masiva participación formal, pero poca participación sustancial. Nuestra hipótesis de partida, de hecho, es que la Iglesia católica fue el hilo conductor por el que se transitó, como si de un puente se tratara, para realizar el cambio del Antiguo al Nuevo Régimen, de la Monarquía absoluta a la soberanía nacional. Consideramos, al igual que plantea Marta Lorente, que el "juramento" -con todas las solemnidades eclesiales- y también el concepto de "vecindad" -aunque en realidad debería haberse usado el de "parroquiano"- son elementos clave para darle legitimidad y credibilidad a las nuevas instituciones democráticas. Una tercera hipótesis, de ser ciertas las dos anteriores, es que las mujeres también juraron de hecho, aunque no de derecho, la Constitución de 1812.

Había que afianzar este incipiente sistema político y jurídico, y la Iglesia católica era la única institución del Antiguo Régimen que permanecía. Además de plantear estas hipótesis de partida, también aportamos un apéndice prosopográfico donde incluimos las biografías de los representantes eclesiásticos por Andalucía en las Cortes gaditanas.

Por último, la metodología empleada es analítica ${ }^{7}$ pues consideramos que los temas abordados se podían estudiar mejor desde esta perspectiva. También, como en otras investigaciones, usamos la perspectiva de género para visibilizar dónde están situadas las personas, no solo los varones. Pensamos que el trasunto sobre las cuestiones metodológicas no puede convertirse en una pugna entre las diversas áreas de conocimiento. La autonomía de una disciplina no viene marcada por su metodología específica sino por las necesidades sociales y de coyuntura en saber más sobre determinadas cuestiones; de hecho, las ramas del conocimiento son móviles y flexibles. Hay que huir del pensamiento único y de las posturas dogmáticas que basan sus argumentos en la autoridad de quien los propone más que en las reflexiones realizadas sobre los datos aportados. ${ }^{8}$ Asimismo, recurrimos al uso de fuentes primarias y secundarias para que la información manejada sea lo más completa posible. Como fuentes primarias, mayoritariamente, hemos recurrido a los Diarios de Sesiones -Generales y secretas-, periódicos de la época y autores coetáneos. Como fuentes secundarias, hemos consultado la doctrina más relevante sobre los temas abordados.

6 «La Nación Española que debía acatar la Constitución no era otra que la compuesta por los "vecinos" (ya no españoles) de los pueblos, vecinos ordenados territorialmente por jurisdicciones (no reformadas en su mayoría), organizados en parroquias» (Lorente 1995: 606).

7 «En la teoría del derecho, la actitud analítica impulsa a quien la asume a no dar por sentado el valor moral de la ley, a exigir los datos empíricos constitutivos del significado de los términos jurídicos, a prestar preferente atención a la estructura lógica del discurso acerca del derecho y a buscar un modelo teórico coherente capaz de explicar unívocamente los acontecimientos sociales y, a la vez, de servir de fundamento a la construcción de argumentos que todos puedan entender y cuyo valor comparativo todos puedan juzgar con independencia de sus propios deseos» (Guibourg 2011).

8 Hay que «procurar no incurrir en frívolos oportunismos, investigar con rigor y profundidad cuestiones cuya importancia actual reclama la contemplación del pasado» (Tomás y Valiente 1977: 88). 
ENCUADRE CONSTITUCIONAL DEL JURAMENTO Y DE LA IGLESIA CATÓLICA

Como es sabido, se nombró una comisión presidida por Muñoz Torrero para elaborar la Constitución, de cuya redacción se encargó a Antonio Sanz Romanillos, quien también había tomado parte en la elaboración del Estatuto de Bayona en 1808. En la extensa Carta Magna promulgada el 19 de marzo de 1812 -de ahí su castizo nombre de "La Pepa"- consta de diez títulos y 384 artículos. En este texto se habla de España -definida según el artículo 10 como la reunión de todos los españoles de ambos hemisferios-, de los españoles -art. 3 "la soberanía reside esencialmente en la Nación»- los tres poderes -arts. 15 a 17, legislativo, ejecutivo y judicial-, las distintas funciones ministeriales y, finalmente, la Constitución se contempla y regula a sí misma. ${ }^{9}$ La Constitución Política de la monarquía española comienza con una tríada finisecular: Dios, Monarquía y patria. Añadiendo cierto toque nostálgico al referirse a la ausencia de Fernando VII "El deseado". ${ }^{10}$

El texto constitucional contiene diferentes fórmulas para los diputados (art. 117), ${ }^{11}$ el Rey (art. 173) ${ }^{12}$ y el Príncipe

9 Sobre el entramado de la redacción de la Constitución de 1812 véanse los tres capítulos dedicados por Luis Sánchez Agesta (1989) al libro de Argüelles.

10 «DON FERNANDO VII, por la gracia de Dios y la Constitucion de la Monarquia Española, Rey de las Españas, y en su ausencia y cautividad la Regencia del Reyno, nombrada por las Córtes generales y extraordinarias, á todos los que la presente vieren y entendieren, SABED: Que las mismas Córtes han decretado y sancionado la siguiente Constitucion política de la Monarquia Española. En el nombre de Dios Todopoderoso, Padre, Hijo y Espíritu Santo, Autor y Supremo Leglslador de la sociedad». Constitución Política de la Monarquía Española de 19 de marzo de 1812. Grafía original de la época. http://hc.rediris.es/01/Constituciones/constituc2.html [febrero 2013]. Los españoles reunidos en las Cortes de Cádiz jalonaron el camino hacia el modelo liberal, pero como puede verse en la introducción a la Constitución de 1812, no copiaron el desinterés de los franceses hacía la monarquía parlamentaria. Sobre esta cuestión nos parece muy interesante la introducción de Miguel Artola al número 1 de la revista Ayer publicado en 1991 (Artola 1991).

11 Art. 117 para los diputados: «En todos los años, el día 25 Febrero se celebrará la última Junta preparatoria, en la que se hará por todos los Diputados, poniendo la mano sobre los Santos Evangelios, el juramento siguiente; ¿Juráis defender y conservar la Religion católica, apostólica, romana, sin admitir otra alguna en el Reyno? .- R = Sí, juro.- // ¿Juráis guardar y hacer guardar religiosamente la Constitucion política de la Monarquia Española, sancionada por las Córtes generales y extraordinarias de la Nacion en el año de mil ochocientos doce? .- R = Sí, juro.- // ¿Juráis haberos bien y fielmente en el encargo que la Nacion os ha encomendado, mirando en todo por el bien y prosperidad de la misma Nacion?- R = Sí, juro.- Si así lo hicéreis, Dios os lo premie; y si no, os lo demande». Constitución Política de la Monarquía Española de 19 de marzo de 1812. Grafía original de la época. http:// hc.rediris.es/01/Constituciones/constituc2.html [febrero 2013].

12 Art. 173 para el Rey: «El Rey, en su advenimiento al Trono, y si fuere menor, quando entre, á gobernar el Reyno, prestará juramento ante las Córtes bajo la fórmula siguiente: N. (aquí su nombre), por la gracia de Dios y la Constitucion de la Monarquia Española, Rey de las Españas, juro por Dios y por los Santos Evangelios que defenderé y conservaré la Religion católica, apostólica, romana, sin permitir otra alguna en el Reyno; que guardaré y haré guardar la Constitucion política y leyes de la Monarquia Española, no mirando en quanto hiciere sino al bien y provecho de ella; que no enajenaré, cederé, ni desmembraré parte alguna del Reyno; que no exigiré jamás cantidad alguna de frutos, dinero ni otra cosa, sino las que hubieren decretado las Córtes; que no tomaré jamás á nadie su propiedad y que respetaré sobre todo la libertad política de la Nacion, y la personal de cada (art. 212). ${ }^{13}$ Estos juramentos mermarán, a lo largo del XIX y parte del $x x$, la libertad de conciencia de quienes tengan la obligación de jurar sin ser creyentes o no pertenezcan a la confesión católica, pero a la vez afianzaran la soberanía nacional y serán el camino para que, a largo plazo, España deje de ser confesional.

Respecto a la importancia de la Iglesia católica, además del su mención en el texto constitucional, el catolicismo mantiene su peso específico en la vida nacional. En realidad, la Constitución de Cádiz continuó la tradición católica del país y ninguno de sus numerosos artículos recoge doctrinas que puedan ser consideradas heterodoxas. ${ }^{14}$ Los diputados de Cádiz no pretendieron, en modo alguno, combatir a la religión católica, sus aspiraciones se centraron en poner los pilares de un Estado moderno.

Sin embargo, llama la atención esa declaración de confesionalidad tan explícita, incluso para la propia historia de España. Años después, Argüelles señaló que este artículo 12 se redactó para «calmar la furia teológica del clero». Esto pudo ser el germen de las dos Españas, la graníticamente confesional, y la liberal afrancesada. El núcleo duro liberal se vio constreñido a dar su asentimiento a la formulación más explícita y terminante de confesionalidad que registra ningún texto constitucional de la historia de Occidente. ${ }^{15}$

Desde un principio encontramos una oposición de la mayor parte del estamento eclesiástico hacia el liberalismo, estas discrepancias aumentarán a lo largo de los años venideros. Como evidencia Cuenca Toribio, esta resistencia clerical no se manifestó tras los decretos de expropiación de los bienes eclesiásticos o la abolición de la Inquisición: «a tenor de ello, quizá pueda aventurarse que su oposición al gobierno constitucional fue primordial y básicamente

individuo. Y si en lo que he jurado, ó parte de ello, lo contrario hiciere, no debo ser obedecido; antes aquello en que contraviniera sea nulo y de ningún valor. Así Dios me ayude y sea en mi defensa; y si no, me lo demande». Constitución Política de la Monarquía Española de 19 de marzo de 1812. Grafía original de la época. http://hc.rediris.es/01/ Constituciones/constituc2.html [febrero 2013].

13 Art. 212 el del Príncipe: «El Príncipe de Asturias, llegado á la edad de 14 años, prestará juramento ante las Córtes baxo la fórmula siguiente: «N. (aquí el nombre), Príncipe de Asturias, juro por Dios y por los Santos Evangelios, que defenderé y conservaré la Religion católica, apostólica, romana, sin permitir otra alguna en el Reyno; // que guardaré la Constitucion política de la Monarquia Española y que seré fiel y obediente al Rey. Así Dios me ayude». Constitución Política de la Monarquía Española de 19 de marzo de 1812. Grafía original de la época. http:// hc.rediris.es/01/Constituciones/constituc2.html [febrero 2013].

14 Prueba de ello es el art. 2 del Proyecto de ley sobre la Responsabilidad de los infractores de la Constitución: «el que conspirase directamente y de hecho á establecer otra religión en las Españas, ó á que la Nacion española deje de profesar la religion católica apostolica romana, será perseguido como traidor y sufrirá la pena de muerte [...]». Diario de Sesiones a Cortes, de 30 de octubre de 1813: 178.

15 Por su parte, Manuel Revuelta González en su tesis doctoral expone que, en otro momento decisivo en la construcción de la España contemporánea, el Trienio liberal, los veinteañistas, para atajar las críticas a su irreligiosidad, recurrieron al famoso artículo, al suponer que «su formulación tajante del catolicismo de la Nación era la refutación más incontestable contra las falacias de los fanáticos prosélitos del absolutismo». Revuelta González, M. 1973. Política religiosa de los liberales en el siglo XIX. El Trienio Constitucional: 122. Madrid: CSIC. Escuela de Historia Moderna. Vid. Revuelta González, M. 2005. La Iglesia española en el siglo XIX: desafíos y respuestas: 39-45. Madrid: Universidad Pontificia de Comillas. 
ideológica, si bien en el trascurso del tiempo esta actitud se reforzó y dobló con razones de clase». ${ }^{16}$

En las Cortes gaditanas se dieron cita un gran número de diputados eclesiásticos de clara tendencia antiliberal. El enorme clericalismo de estas Cortes cuasi conciliares hizo que se redactaran algunos artículos que hacen referencia a "la misa" como si fuera una ceremonia más del Estado (arts. 48, 71, 87). A su vez, el art. 249 permite que los Eclesiásticos continúen gozando del fuero de su estado en los términos recogidos por la ley. Para que la Iglesia católica tuviera esta preeminencia en la Constitución, además del clericalismo de las Cortes, fue determinante el espíritu confesional de la sociedad española de la época. ${ }^{17}$

En el texto gaditano, por mor del consenso, hace referencia a la instrucción pública: por primera vez emerge un marco normativo general para la instrucción pública en España. ${ }^{18}$ Del Título IX De la Instrucción Pública (arts. 366 a 371), destaca un plan uniforme para todo el reino, escuelas de primeras letras y la inspección a cargo del Gobierno. Las Cortes son las encargadas de regular la instrucción pública, y será responsabilidad de los Ayuntamientos cuidar de las primeras letras y centros educativos (art. 321). La responsabilidad de las Diputaciones, de otro lado, será la de promover la educación de la juventud (art. 335). La guerra contra el francés y la Constitución de 1812 hicieron posible una enseñanza pública, católica, apostólica y romana: quedamos más alejados del laicismo francés que de la confesionalidad romana.

Además de la declaración de confesionalidad católica realizada por el art. 12, el art. 366 establece como enseñanza básica el catecismo de la religión católica. ${ }^{19}$ Interesa resaltar la proposición de Nicolás García Page, diputado por Cuenca en las Cortes de 1813 y cura párroco de la diócesis de San Andrés. En su intervención del 9 de octubre insistió en la necesidad de elaborar un plan uniforme de instrucción pública para todo el Estado. Asimismo, pedía que se publicara

un catecismo nacional para la enseñanza de la religión católica en todas las escuelas de la Monarquía española [...] Seis reverendos obispos, de los más respetables por su piedad y literatura, examinaran este catecismo, y sus aprobaciones se estamparán en todos los ejemplares que se impriman. ${ }^{20}$

Un artículo bastante polémico fue el 371, redactado en los siguientes términos: «Todos los españoles tienen libertad de escribir, imprimir y publicar sus ideas políticas sin necesidad de licencia, revision ó aprobacion alguna anterior á la publicacion, baxo las restricciones y responsabilidad

16 Cuenca Toribio 1978: 28.

17 Pérez Vilariño 1973: 21.

18 Sanchis Vidal 2009: 397.

19 En plena guerra de la Independencia, nos encontramos con dos posturas antagónicas: por un lado, el liberalismo, que incluía a liberales e ilustrados que querían la modernización, y por otro lado, los absolutistas del Antiguo Régimen, donde se reunieron el clero y la nobleza que buscaban la vuelta al absolutismo con la monarquía de Fernando VII. La Constitución de 1812 fue el resultado de un compromiso entre fuerzas antagónicas y una vez expulsados los franceses, Fernando VII declaró nula la Constitución. Es comprensible, por tanto, encontrar una constitución de corte confesional con medidas de signo liberal como la abolición de la Inquisición o la libertad de imprenta (Martínez Blanco 1994: 42 y ss.).

20 Diarios de Sesiones a Cortes, 9 de octubre de 1813: 101. que establezcan las leyes». ${ }^{21}$ La libertad de imprenta fue el germen de la libertad de expresión, configurándose como la ausencia de censura previa, lo que llevó también a la supresión de los juzgados de imprenta precedentes a la impresión. Dicha libertad se refieres únicamente a las ideas políticas. ${ }^{22}$ La libertad de imprenta posibilitó la proliferación de los "catecismos políticos". ${ }^{23}$ Los catecismos civiles y políticos habían sido muy utilizados en el país galo como instrumento para explicar de forma sencilla y precisa los derechos y deberes del hombre -no como masculino universal-, y así asumir el protagonismo obtenido por la ciudadanía a través de la democracia. Importados de Francia se tradujeron y copiaron, sirviendo de base para los catecismos políticos españoles. ${ }^{24}$ Era contradictorio que, siendo una copia de la llustración francesa, contuvieran tantas opiniones negativas hacia el pueblo galo; la explicación es sencilla si se recuerda que se estaba en guerra contra el ejército napoleónico. Era difícil defender un nuevo orden político y social que provenía del mismo lugar de donde era el ejército invasor; y más difícil si cabe, aceptar los beneficios de la llustración. ${ }^{25}$

El mismo año en que se promulga la Constitución se publica en Madrid un Catecismo político arreglado a la Constitución de la Monarquía Española: Para ilustración del pueblo, instrucción de la juventud y uso de las escuelas de primeras letras, ${ }^{26}$ en él se explicaba, de manera sencilla y con ejemplos, la Constitución de 1812. También se empleó para cubrir la obligación del art. 368, que exigía la explicación de la Constitución en las Universidades. ${ }^{27}$

21 Constitución Política de la Monarquía Española de 19 de marzo de 1812. Grafía original de la época. http://hc.rediris.es/01/ Constituciones/constituc2.html [febrero 2013].

22 Souto Paz 2003: 372; Sanchis Vidal y Ramos Rovi 2012.

23 J. Muñoz Pérez destacó que para la transmisión de ideas se recurrió a los "catecismos" por considerarlos un método sencillo y elemental para la formación política del pueblo. Cfr. Muñoz Pérez 1987: 196. Es muy interesante el trabajo de Capitán Díaz (1978): passim. Véase además Ramos Santana 2004: passim.

24 Entre los catecismos políticos cabe destacar: "El catecismo liberal y servil" de 1814; y "Breve Catecismo político-español-constitucional que a imitación del de doctrina cristiana, compuesto por el Sr. Reinoso, presenta al público". Con la vuelta de Fernando VII, los catecismos políticos fueron, la mayoría, incautados, el "Catecismo de los derechos del hombre" de 1814 fue prohibido formalmente (Capitán Díaz 1991, vol. I: 1014-1016).

25 «El catecismo político está por hacer [...] La constitución del estado, los derechos y obligaciones del ciudadano, la definición de las leyes, la utilidad de su observancia, los perjuicios de su quebrantamiento: tributos, derechos, monedas, caminos, comercio, industria; todo esto se puede y debe comprender en un librito del tamaño de nuestro catecismo por un método sencillo, que cierra el paso a todos los errores contrarios. Se nos inculcan en la niñez los dogmas abstractos de la teología, ¿̇y no se nos podrían enseñar los principios sociales, los elementos de la legislación y demostrar el interés común e individual que nos reúne? [...] Esta enseñanza elemental y tan fácil ha de ser por consiguiente común a todos los ciudadanos: grandes, pequeños, ricos y pobres; deben recibirla igual y simultáneamente» (Puelles Benítez 1991).

26 Ibídem: 36, nota 55.

27 Art. 368: «El plan general de enseñanza será uniforme en todo el Reyno, debiendo explicarse la Constitucion política de la Monarquia en todas las universidades y establecimientos literarios donde se enseñen las ciencias eclesiásticas y políticas». Vid. Constitución Política de la Monarquía Española de 19 de marzo de 1812 (grafía original de la época), http://hc.rediris.es/01/Constituciones/constituc2.html/ [febrero 2013]. 
Pero antes de que se desarrollase la Constitución había que afianzarla, que el pueblo la hiciera suya. La Constitución de 1812 fue el primer texto fundamental de la nación en el que se declaran y regulan los derechos de los españoles. Ciertamente que se tratan de derechos muy limitados; el mérito de la Constitución estribó en declararlos por vez primera, no como gracia benévola y paternalmente por el rey, sino declarados imperativamente por la voluntad de la nación. Para que la Constitución y la soberanía nacional tuvieran suficiente refrendo moral entre la población se arbitró el juramento, del que pasamos a ocuparnos.

\section{IMPORTANCIA DEL JURAMENTO PARA LA SOBERANÍA NACIONAL}

La pugna entre la confesionalidad y la libertad religiosa en el constitucionalismo español tiene una larga tradición histórica que perdura hasta nuestros días. ${ }^{28}$ Los diversos análisis que se han realizado de la Constitución de 1812 han concluido con resultados diferentes fruto de los diversos enfoques de las investigaciones. Consideramos que se establece, jurídicamente, una "severa confesionalidad", 29 incluso planteamos, coherentes con la primera hipótesis, que esta circunstancia era buscada por los unos-fernandinos y absolutistas- y permitida por los otros -doceañistas y liberales-. En realidad, a pesar de lo que pudiera parece a primera vista, a todos los diputados presentes beneficiaba la pervivencia de una institución del Antiguo Régimen para transitar hacia la contemporaneidad.

Por otro lado, según lo dispuesto en el art. 12 de la Constitución, España es y será católica, apostólica y romana. Esta declaración de confesionalidad no solo refleja la moral social de la época sino que, además, es un elemento de unidad frente al invasor en plena guerra de la Independencia. La Iglesia católica representará para los conservadores la elevación moral frente a las ideas de las Revoluciones liberales, americanas o francesa. Para los liberales será el inesperado puente por el que transitar desde el Antiguo hacia el Nuevo régimen. En todo caso, estamos ante una institución poderosa que fue, a su pesar, quien posibilitó el ascendente moral que se necesitaba para que la Constitución de 1812 adquiriera el refrendo necesario, por parte de los aún súbditos, para dar comienzo al periodo constitucional español.

Tanto el preámbulo como el art. 12 encuadran la confesionalidad católica y la intolerancia religiosa hacia cualquier otra cosmovisión -sea sagrada o profana-. ${ }^{30}$ De otro lado, hemos fijado un iter para este apartado: 1) analizar el juramento realizado por la Regencia; 2) analizar el juramento realizado por los diputados constituyentes; y 3) analizar el juramento realizado por la nación. El objetivo es comprobar la recepción que tuvo la Constitución de 1812 en la ciudadanía de la época ante un cambio de paradigma político, social y jurídico, y el papel jugado por Iglesia católica en dicho tránsito.

\section{Hera 2008.}

29 Ibídem: 94

30 «La Religion de la Nacion Española es y será perpetuamente la Católica, apostólica, romana, única verdadera. La Nacion la protege por leyes sabias y justas, y prohibe el exercicio de qualquiera otra». Constitución Política de la Monarquía Española de 19 de marzo de 1812. Grafía original de la época. http://hc.rediris.es/01/ Constituciones/constituc2.html [febrero 2013].

\section{a. Juramento de la Regencia:}

El primer juramento del que nos ocupamos es el formulado por los miembros de la Regencia en la Isla de León, el 29 de enero de 1810. En él se puede apreciar que la mayor preocupación era poner de relevancia, sin ningún género de dudas, la religión católica. Esta postura, creemos, estaba destinada a salvar la monarquía para Fernando VII -así lo expresará después la Constitución-, que a invadir la conciencia de otras cosmovisiones. ${ }^{31}$ De hecho, la moral imperante obviaba otro sistema axiológico que no fuera el católico, apostólico y romano.

Todo el proceso constitucional quedó imbuido de una inequívoca y excluyente cosmovisión católica. Quizá una de las razones fuera la defensa a ultranza que el Vaticano tuvo históricamente hacia la monarquía española desde el Ilamado "descubrimiento de América" y en el Tratado de Tordesillas. Asimismo, no debemos desdeñar el poder económico que la Iglesia detenta a lo largo de la historia, era pues, un valor seguro -en tiempos inciertos- tener a católicos y eclesiásticos en la Junta Central, en el Consejo de Regencia y en las futuras Cortes constituyentes. Quizá otra razón fuera que las cosmovisiones profanas, y los procesos de laicización tan en boga entre los afrancesados, provenían del país que en ese momento ocupaba, beligerantemente, la península.

Tan entretejida estaba la moral católica en el imaginario social de la España del XIX que cuando se instituyó el juramento no se consideró que se estuviera excluyendo a nadie de la Junta de Regencia por sus creencias. Se pensaba que toda persona "de bien" era católica. Como si la confrontación entre la conciencia y el deber del juramento impuesto no se pudiera dar. Quizá con el afán de transmitir a la ciudadanía el refrendo de la Iglesia católica al proceso constituyente, el gobierno comenzó una clericalización de la que no participaban todas las instituciones como se constata en Sevilla o Cádiz. ${ }^{32}$

\section{b. Juramento de los diputados constituyentes}

A primera hora de la mañana del 24 de septiembre de 1810 en San Fernando los diputados que habían salido electos en las urnas oyeron la misa del Espíritu Santo y un sermón exhortando a cumplir con su deber. Concluida la ceremonia,

31 «¿Juráis a Dios y a Jesucristo crucificado, cuya imagen tenéis presente, que en el desempeño de la regencia de España e Indias, para que habéis sido nombrado por la representación nacional legítimamente congregada en esta Isla de León, haréis cuanto esté de vuestra parte para conservar en España la religión Católica Apostólica Romana sin mezcla de otra alguna, expeler los franceses de nuestro territorio, y volver al trono de sus mayores al rey Nuestro Señor Don Fernando VII, y en su defecto sus habientes derecho según las leyes fundamentales de la monarquía, no perdonando medio ninguno de cuantos puede practicar la industria humana para conseguir estos sagrados fines, aun a costa de vuestra propia vida, salud y bienes?» (Comence 1909: 177).

32 «Aunque los decretos gaditanos impedían al clero el acceso a los cabildos municipales, no prohibían su representación como candidatos para las elecciones de compromisarios. No es de extrañar, pues, que los párrocos hispalenses se mostrasen muy bulliciosos en la primera vuelta de los sufragios, conforme expresarían más tarde algunos escandalizados órganos publicísticos. De esta forma, detectamos una de las características que configuran la historia de la Sevilla constitucional: su acentuada clericalización, nada sorprendente si se repara en la solidez de los pilares del poder económico y, sobre todo, social que detentaba el clero hispalense» (Cuenca Toribio 1973: 30). 
en la Real Isla de León, se exigió a los Diputados realizar un juramento de fidelidad. ${ }^{33}$ Una vez concluidos los actos religiosos, salieron los asistentes y se dirigieron a celebrar la primera sesión. ${ }^{34}$ Se pretendía fidelizar a todos aquellos que iban a participar en la elaboración del texto constitucional, de la misma manera que ya se hizo con la Regencia.

Si nos atenemos al contenido de las sesiones, en la mente de nuestros parlamentarios gaditanos estaban muy presentes los discursos de los representantes franceses de la Asamblea Nacional. Sin embargo, por otro lado, en el acto del juramento hemos percibido una total sumisión a la tradición española en la adhesión incondicional y el respeto a la Monarquía y a la religión católica. Distinguimos, pues, un deseo de conservar la esencia de la "tradición española" según el imaginario de la época: Dios, patria y rey.

Sin solución de continuidad, tras escuchar los Evangelios y jurar el cargo salieron de la Iglesia, cruzaron la calle y entraron en el Teatro para dar comienzo a la historia constitucional española. En su sesión inaugural, celebrada en San Fernando el 24 de septiembre de 1810, las Cortes extraordinarias proclamaron la soberanía nacional y la división de poderes, principiando de manera significativa una labor que se extendió a lo largo de un total de 1.810 sesiones, la mayoría de las cuales se realizaron entre la Isla del León y Cádiz, hasta que se trasladaron a Madrid -donde las sesiones comenzaron el 15 de enero de 1814, hasta el decreto de 4 de mayo del mismo año-..$^{35}$

Se abordaron reformas políticas, administrativas, sociales y económicas. Resulta cuanto menos paradójico que fueran unos metros la única separación física entre el Antiguo Régimen y el Estado moderno; esa era la distancia que mediaba entre la Iglesia donde se realizó el juramento y el Teatro donde se iniciaron las sesiones parlamentarias.

Pareciera que a finales de septiembre de 1810 comenzó una partida de ajedrez jurídica donde las piezas blancas las movían los liberales. A simple vista pudiera parecer que los juramentos, serán variados, eran un menoscabo de la libertad de conciencia para quienes no fueran católicos. ${ }^{36}$

33 «¿Juráis la Santa Religión Católica, Apostólica, Romana, sin admitir otra en estos Reinos? // ¿Juráis conservar en su integridad la nación española y no omitir medio para liberarla de sus injustos opresores? // ¿Juráis conservar a nuestro muy amado Soberano Don Fernando VII todos sus dominios, y en su defecto a sus legítimos sucesores, y hacer cuantos esfuerzos sean posible para sacarlo del cautiverio y colocarlo en el trono? // ¿Juráis desempeñar fiel y lealmente el encargo que la nación ha puesto a vuestro cuidado, guardando las leyes de España, sin perjuicio de alterar, moderar, y variar aquellas que exigiesen el bien de la nación? Y habiendo respondido todos los señores diputados: sí juramos, pasaron de dos en dos a tocar el Libro de los Santos Evangelios. Tras el juramento, se cantó el veni creator, y un solemnísimo te deum» (Comence 1909: 215).

34 «La explicación de todo este ceremonial y temática religiosa no reside en el simple hecho de que los diputados eclesiásticos ocupasen gran parte de los escaños. Responde más bien al espíritu confesional de la época. La religión y sus prácticas eran una parte esencial de la vida nacional y, en consecuencia, de su vida pública. Se trata de una sociedad tradicional sacra» (Pérez Vilariño 1973: 21).

35 En 1814, las Cortes debatieron la propuesta realiza por los Padres del Oratorio de San Felipe Neri de Cádiz en relación a la aprobación de una partida económica para devolver el templo a su estado original. Durante tres años había sido la sede de las Cortes Generales y extraordinarias. Diario de Sesiones a Cortes, de 9 de abril de 1814: 288 .

36 Pero también fue una situación atípica para quienes, siendo católicos, no eran liberales (Rodríguez López-Brea 2002: 7 y ss).
Y así sucedió: su conciencia volvía a estar vulnerada, no menos de lo que ya les pasaba durante el Antiguo Régimen con el Santo Oficio. La diferencia es que, ahora, la cuestión estaba enfocada teleológicamente, como en el ajedrez; el objetivo era ganar la mayor cuota de libertad e igualdad constitucional para el mayor número de personas. $\mathrm{Y}$, con todos los fallos e imperfecciones, eso fue lo que se consiguió: la soberanía nacional.

\section{c. Juramento de la nación}

En este apartado, a diferencia de los epígrafes anteriores, nos ocupamos del juramento realizado por las autoridades y el pueblo tras haberse promulgado la Constitución. Se trata de una ceremonia que podríamos distribuir en dos tiempos: 1) publicación de la Constitución a través de su lectura en la plaza mayor o lugar donde acuerden las autoridades; ${ }^{37}$ 2) jura de la misma en una misa realizada en la Catedral o Iglesia donde acuden los "españoles" y "vecinos". También asistirán, en realidad, las mujeres y los transeúntes. Incluso se pensó en la participación de los presos en la jura de la Constitución.

Cabría preguntarse ¿quiénes eran considerados españoles?, ¿quiénes tenían derecho al sufragio? Mientras los varones habían realizado el cambio de súbditos a ciudadanos las mujeres quedaban ancladas en el pasado. De otro lado, ¿pasaron los parroquianos a ser considerados vecinos para la Administración? Si antes solo juraba el monarca, ahora se pretende que jure la ciudadanía, tanto personas como instituciones. Con vista y habilidad, los diputados doceañistas se marcan como objetivo primordial que el incipiente sistema constitucional tuviera una oportunidad a través de un refrendo mayoritario por parte de la población. Se necesitaba un punto de estabilidad, el que podía dar la Constitución de 1812.

La tradición confesional, asentada durante siglos, posibilitó unas ceremonias de juramento que alentadas por un enemigo común, el francés, fueron masivas en parroquias o catedrales, según se decidiera en los ayuntamientos. Apelar a la tradición en un momento tan convulso de guerra y profunda crisis económica propiciaba un escenario patriótico donde no cabía otra cosa que jurar la Constitución. Inteligente maniobra. Era una ceremonia civil hábilmente hospedada, infiltrada, en otra religiosa, la Misa, pidiendo el refrendo moral para comenzar el camino hacia la separación entre el Estado y la Iglesia. Mientras, la mayoría de la población creía que estaba apoyando a la monarquía, a la fe católica. Glorioso oxímoron.

Las ceremonias de jura constitucional se vieron dificultadas por dos razones: por la falta de disponibilidad económica debida a la profunda crisis $^{38}$ y por la presencia de tropas francesas en algunas de las localidades donde se iba a

37 «Mandamos á todos los españoles nuestros súbditos, de qualquiera clase y condición que sean, que hayan y guarden la Constitución inserta como ley fundamental de la Monarquía». Decreto por el cual se manda imprimir y publicar la Constitución política de la Monarquía, y se señala la fórmula con que la Regencia debe verificarlo. Cádiz 18 de marzo de 1812 (Fernández Martín 1885).

38 «Esta crisis de 1812 se considera la más virulenta de las vividas hasta entonces en los siglos XVIII Y XIX» (Moreno Fernández 2009: 18). 
realizar el juramento. Serán los ayuntamientos, según la disponibilidad económica y la situación del asedio francés, los que dispongan cómo y dónde se harán las ceremonias de jura. Dependiendo de lo prolijo de las actas consistoriales se ha sabido cómo fue, en cada población, la ceremonia pública de lectura y juramento constitucional. ${ }^{39}$

Como hemos podido comprobar, tras los datos analizados, hacer de la Constitución algo propio, cercano, para la ciudadanía fue una tarea bien planeada, delimitaron el espacio y las fórmulas a emplear y prepararon una puesta en escena con un ritual que les resultara cercano. Si por nación se entendió el territorio ocupado por los ciudadanos, el segundo paso fue buscar, hábilmente, que la Iglesia les prestara su potestad moral a través del juramento y las ceremonias. Así, se consiguió que:

- El juramento se convirtiera en un rito de paso del Antiguo al Nuevo Régimen. ${ }^{40}$

- La vinculación moral fuera infranqueable, a través de una propuesta que aglutinó a las Cortes constituyentes. $^{41}$

- La mayoría del pueblo, incluidas las personas que no podían votar, estuvieran presentes en la ceremonia de la jura. ${ }^{42}$

Según el apartado segundo del Decreto que prescribía las solemnidades para la jura del texto constitucional se: reunirá a los vecinos en sus respectivas parroquias; celebrará una Misa solemne; leerá la Constitución antes del Ofertorio; y prestará juramento por todos los vecinos y el clero. Aun en el caso hipotético de que se refieran solo a varones, las mujeres no tuvieron prohibido el paso a la parroquia para escuchar la Misa. Por tanto, ellas, las ciudadanas de segunda, al igual que los transeúntes, pudieron jurar la Constitución debido a la fórmula del juramento que disponía: «responderán todos los concurrentes: Sí juro». ${ }^{43}$

En el apartado quinto del citado Decreto se prescribe una visita a las cárceles por los Tribunales para poner en libertad a los presos que no tengan pena corporal. ${ }^{44}$

También se ocuparon del juramento del ejército, recogido en el Reglamento provisional para la Milicia Nacional fija del Reino. El art. 54 del capítulo VII está dedicado al juramento,

39 López 2011: 156 y ss.

40 Como recoge el Sr. Villanueva, diputado en las Constituyentes, «en lo general se observó la mayor satisfacción y alegría. No faltaban empero descontentos ocultos que miraban con desagrado hasta las gracias que dábamos a Dios por la conclusión de esta obra». Ibídem: 727.

${ }^{41}$ «El papel inspirador que el espíritu religioso que ejercía sobre la actual revolución [...] buen exponente al fin de cuentas, de la función retórica que desempeñó la religiosidad en el designio patrióticopolítico patrocinado por las Cortes» (Morán Orti 1994: 19).

42 «Decreto en que se prescriben las solemnidades con que debe publicarse y jurarse la Constitución política en todos los pueblos de la Monarquía, y en los exércitos y armada: se manda hacer visita de cárceles con este motivo». Cádiz 18 de marzo de 1812 (Fernández Martín 1885: 728-731).

43 Fórmula del juramento: «¿Juráis por Dios y por los Santos Evangelios guardar la Constitución política de la Monarquía Española, sancionada por las Córtes generales y extraordinarias de la Nacion, y ser fieles al Rey?" Decreto en que se prescriben las solemnidades con que debe publicarse y jurarse la Constitución política en todos los pueblos de la Monarquía, y en los exércitos y armada: se manda hacer visita de cárceles con este motivo. Cádiz 18 de marzo de 1812 (Fernández Martín 1885: 729).

44 Ibídem: 730. en el mismo se especifica cómo y con quién debe realizarse el mismo. La fórmula incluye el uso de las armas para defender la religión católica, apostólica y romana -en primer lugar-, así como la defensa de la Constitución política y de la Monarquía. ${ }^{45}$ Cabría cierto paralelismo, mutatis mutandi, con las fórmulas que realizan algunas religiones para su defensa, también a través de las armas.

En este juramento en particular, el dedicado a la nación, fue donde la Iglesia, el catolicismo, hizo más por validar la Constitución y el Nuevo Régimen que en cualquiera de las otras juras que hemos analizado. ${ }^{46}$ Sin embargo, el Estado no hizo "real el deseo "nacionalizador" de la Iglesia católica»" ${ }^{47}$ ni tampoco mantuvo el Tribunal de la Inquisición.

Por último, el 24 de mayo de 1812 se promulga el Decreto en que se fija el modo con que el clero y pueblo han de jurar la Constitución política en toda la Monarquía..$^{48}$ En él, pueblo y clero "á una voz y sin preferencia alguna» jurarán guardar la Constitución. Después, para su cumplimiento, se dispone que se imprima, publique y circule.

Los dos Decretos de 18 de marzo, y el Decreto de 23 de mayo de 1812 apuntaron hacia la legitimación de la Constitución de La Pepa a través de la Iglesia católica. Emplearon las parroquias y las Misas para que concurrieran el mayor número de personas. No fueron españoles tan solo los que juraron, ni vecinos, puesto que también lo hicieron las mujeres y los transeúntes. Quizá haya sido uno de los textos constitucionales más refrendados de la historia española. Evidentemente no podemos afirmar esto desde un punto de vista jurídico, ni tampoco considerar, como ya hemos expuesto, que el refrendo lo realizó la recién estrenada ciudadanía; ironías del destino, sí fue un refrendo masivo de la población que provino de la feligresía, desde cada una de las parroquias donde celebraron las Misas que incluían el juramento a la Constitución.

\section{LA COMPLEJA ALINEACIÓN DEL CLERO ANDALUZ.}

En las Cortes gaditanas nunca hubo una estructura ni ideológica y ni organizativa en ninguna de las agrupaciones. Sólo metafóricamente, como nos advierte Caballero Mesa,

45 «¿Jurais á Dios emplear las armas que la Pátria pone en vuestras manos en defensa de la religion católica apostolíca romana, la de este pueblo y su término, y en la conservacion del órden interior: guardar y hacer guardar, si alguna vez os compitiese, la Constitucion Política de la Monarquía: ser fieles al Rey, custodiar y defender su persona sagrada é inviolable: sujetaros y hacer que vuestros súbditos se sujeten á la Constitucion y leyes militares: Obedecder exactamente si n excusa ni dilación á vuestros jefes: seguir constantemente las banderas nacionales, defendiéndolas hasta morir, no abandonando jamás el puesto que se os confie, ni al jefe que os estuviese mandando en cualquiera ocasión del servicio, y guardar la debida consideración á los demás españoles? Sí juro. - El capellán contestará: yo en virtud de mi ministerio pediré á Dios que si así lo hicieseis os ayude; y si no, os lo demande». Diario de Sesiones a Cortes, de 27 de marzo de 1814: 183.

46 «La Iglesia entendió que el primer y preexistente fundamento constitucional era el católico, y que por ello, ningún acto o disposición civil podía apartarse de la comprensión que sobre cualquier cosa tuviera la Iglesia. Si se rompía la identidad, el juramento constitucional dejaba de prevalecer frente al debido a la Iglesia, esto es, el voto de los eclesiásticos que, a su vez, dejaban de ser correas de transmisión del orden constitucional» (Lorente 1995: 625).

47 Ibídem: 626.

48 Fernández Martín 1885: 731. 
se puede hablar de partidos. Existía antes de que se reuniera el Congreso una formación con un programa único a la que se ha llamado pre-partido liberal. De los demás, absolutistas o serviles, conservadores y radicales, no puede decirse tanto. Cabe tan sólo hablar de minorías cohesionadas, que en ocasiones consiguen aglutinar en torno a ellos a importantes segmentos de la Cámara. ${ }^{49}$

En estas Cortes había una notable presencia de los estamentos privilegiados en detrimento de la burguesía. Empezando con los eclesiásticos, no hay que olvidar el arranque de hondo patriotismo que se apoderó de la inmensa mayoría de los españoles durante la Guerra de la Independencia. Por aquellos días, en todas las juntas provinciales figuraban religiosos. ${ }^{50}$ Además, se hace necesario desechar falsas interpretaciones de una postura unánime del clero de monolitismo ultramontano y cerrazón al ideario ilustrado en las Cortes. ${ }^{51}$ Entre un 30 y un 32\% de los diputados eran eclesiásticos y, en Andalucía, llegaban a ser un tercio del total $-33 \%$ y $34 \%$ de los activos, desde los obispos de Sigüenza y Guadix-Baza a párrocos como el famoso Vicente Terrero de Algeciras, pasando por presbíteros, canónigos, prebendados y beneficiados- ${ }^{52}$

Como hemos apuntado, Caballero Mesa habla de tres grupos parlamentarios, y respecto a los representantes andaluces establece un primer grupo liberal formado por Morales de los Ríos, Aguirre, Porcel, Alcalá Galiano y González. Dueñas bascula entre éste y el conservador. Un segundo grupo de adscripción conservadora integrado por Cerero, Morales Gallego, Garcés y Salas. Terrero, radical en las reformas sociales y políticas, y moderado en las institucionales, hace de bisagra con el liberalismo. $Y$ un tercer grupo absolutista integrado por Gómez Fernández, Valiente, Jiménez del Guazo, Jiménez del Hoyo y Torres

\footnotetext{
49 Caballero Mesa 1991: 191.

50 «Es interesante estudiar las profesiones de estos diputados para tener conciencia de las preferencias del pueblo español a la hora de elegir sus representantes. Se ve que en determinadas zonas españolas hay todavía una absoluta confianza en el Clero, mientras que en otras domina una especie de feudalismo de tipo burocrático, y son los que ocupan los cargos oficiales los preferidos. De todas maneras había una supremacía del Clero sobre otras profesiones; llegan a 90 los diputados eclesiásticos» (Solis 2000: 253).

51 También estaban allí presentes ardientes partidarios del régimen liberal, "pues lo hubo entre ellos quienes calificara de herejía política poner en duda que la soberanía no residiese en la nación. Desde 1808-1812 el movimiento patriótico y regenerador contra los franceses, la repulsión a las corruptelas palaciegas y al favoritismo fueron unánimes en todas las clases y más particularmente entre los individuos del clero». Sin embargo, por más de un artículo de la nueva constitución hubiese proclamado «la religión católica, apostólica, romana, como única verdadera y como de ser la única verdadera y como de ser la exclusivamente admitida en los dominios españoles, el sagaz instinto eclesiástico no tardó en vislumbrar la nube que se le venía encima y preparase el clero no sólo para la defensa sino para el ataque contra las nuevas instituciones» (Lafuente 1882, vol. VI: III).

52 «Los catedráticos de Universidad tienen, con ser muchos menos en proporción, un número más elevado: quince de ellos llegan a la Isla de León como representantes del pueblo. Entre ellos los hubo de todas las materias, no faltando uno de Teología, don Martiniano Juan de la Torre, que con su prestigio bien pudo avalar al Congreso en una materia tan delicada. Por eso es injusto decir que las Cortes de 1812 no sabían Teología; alguno no, pero, en compensación, allí estaba don Martiniano para sacarles de su ignorancia» (Solis 2000: 254). Aquí lo hemos incluido como eclesiástico.
}

Guerra. ${ }^{53}$ Aparte, queda un extenso y nebuloso conjunto de diputados con posturas indefinidas.

Respecto a la filiación católica de los 26 eclesiásticos que ocuparon escaño por Andalucía diremos que, dentro de los Ultramontanos -los más conservadores- encuadramos a: Alaja, Moreno y Garino, Rodríguez de Bárcena. Dentro del grupo de los Católicos formales -que siguen los ritos aprendidos- tenemos a Terrero Monesterio. Por último, Jiménez Hoyo estaría en el grupo de Católicos reformistas -aquellos que formulan algunos cambios-.

Ocupan un lugar destacado en los debates parlamentarios, los dedicados a la abolición del Santo Oficio. Menéndez Pelayo subrayó en su momento la "extraña unanimidad" con que amigos y enemigos de la Inquisición afirmaban que el pueblo la quería (sic). ${ }^{54}$

Otra cuestión fundamental fue, igualmente, la discusión del texto constitucional. A comienzos de marzo de 1811, una comisión integrada por diputados liberales (como Argüelles y Muñoz Torrero), reaccionarios (Gutiérrez de la Huerta y Valiente) y otros comenzó a trabajar en el proyecto. La comisión proponía que se dijera que «la religión de la Nación española es la católica, apostólica, romana, única verdadera, con exclusión de cualquier otra», tal y como apareció en la redacción del texto definitivo. Sobre la cuestión se volvió a debatir en las Cortes. En el artículo primero se hablaba del delito cometido por aquellos que de palabra o por escrito intentasen persuadir que la constitución no debía ser obedecida y cumplida en el caso en que obliga a todos los ciudadanos su ejecución. Además, según apuntó el señor Cevallos, diputado por Córdoba, "la constitución no solo prohíbe que se introduzca otra religión, sino también que se cometa otro delito contra ella, de aquí deduzco yo, que se deben imponer penas, no solo al que conspire, sino al que cometa cualquier otro delito". ${ }^{55}$

Como hemos visto, a pesar de que un número considerable de acuerdos adoptados por las Cortes Gaditanas eran favorables a la religión católica, su obra fue objeto de múltiples resistencias por extensos núcleos eclesiásticos. ${ }^{56}$ También es constatable que a partir del texto constitucional la Iglesia comenzó a perder poder, económico y político.

53 Ibídem: 196; Ramos Rovi y Ventura Rojas 2009.

54 «La nación -exclama del diputado Ximénez Hoyo, que no figuraba ciertamente, en el bando de los serviles- no está compuesta solamente de una porción de personas amantes de la novedad o temerosas de un freno que las contenga... Nosotros sabemos lo que pasa, y nadie ignora lo que los pueblos piensan... Es general, el voto de la nación sobre el restablecimiento de un Tribunal, que creen absolutamente necesario para conservar pura la religión católica... Yo, por mi parte, protesto, y protestamos los diputados de Córdoba, que jamás votaremos la extinción del tribunal de la Inquisición, porque no es este el voto de los que nos han dado sus poderes para representarlos en este Congreso" (Menéndez Pelayo 1992, II: 992). Diario de Sesiones a Cortes, legislatura de 1813, 5.VII. 1813: 5.607-5.610.

55 Diario de Sesiones a Cortes, legislatura de 1813, VIII. 1813: 5.991.

56 «La dimisión del obispo de Orense a raíz de la declaración de las Cortes de residir en ellas la soberanía nacional, que consideraba atentatoria a las tradiciones y leyes patrias, abrió un camino por el que se adentrarían, tiempo adelante, gran número de prelados y sacerdotes. Con la extinción de la Inquisición por los legisladores gaditanos, el antagonismo entre el estamento eclesiástico y el sistema constitucional alcanzó su máxima cota» (Cuenca Toribio 1978: 26-27). 


\section{APÉNDICE PROSOPOGRÁFICO}

En este apartado pretendemos incluir a todos aquellos eclesiásticos que en algún momento del periodo constitucional (1810-1812) ocuparon escaño por Andalucía. Algunos repitieron escaño durante la legislatura de 1812-1813. La prosopografía, como es sabido, se dedica al estudio de la biografía de las personas, del colectivo al que pertenecen, aplicado a su discurso o al área de conocimiento que se pretenda analizar. Este estudio pormenorizado de los diputados, consideramos que tiene suma importancia al permitir localizarlos por su ámbito geográfico -Andalucía-, religión -católica-, profesión -cualquiera de los órdenes sacerdotales-, y otros datos que, de manera indirecta, nos aportan una información inestimable para el análisis de sus discursos durante las sesiones parlamentarias.

Este apartado supone una visibilización de los discursos de manera "localizada" desde un punto de vista ideológico, además de la cuestión puramente geográfica. Los datos biográficos ayudan a contextualizar los afanes que se tenían en función de la clase social a la que pertenecían los diputados o la importancia que la confesión católica tuvo durante el periodo constituyente. Con esta información, la lectura de sus discursos y las aportaciones en el parlamento se puede realizar desde otra perspectiva diferente, distinta, mucho más rica y comprensiva de sus intenciones política, siempre unidas a su filiación religiosa.

\begin{tabular}{|l|}
\hline \multicolumn{1}{|c|}{ CÁDIZ } \\
\hline Diputados titulares \\
\hline TERRERO MONESTERIO, Vicente: Nació en San Roque el 18- \\
III-1776. Fue examinador sinodial del arzobispo de Sevilla y del \\
obispado de Málaga y Ceuta, así como cura de Algeciras. A lo largo de \\
sus discursos mostró un carácter controvertido y algo extravagante. \\
Fue diputado propietario por la provincia gaditana (19-VIII-1810) y \\
cesó en el cargo en septiembre de 1813. Participó muy activamente \\
y, aunque suele considerársele como conservador, fue más bien un \\
tibio liberal con ribetes conservadores. Menéndez Pelayo lo consideró \\
como una especie de "demagogo populachero" y Pérez Galdós lo \\
confundió con Tenreyro en su Episodio Nacional de Cádiz. Defendió \\
la potestad del legislativo siguiendo los postulados del P. Mariana, \\
criticó duramente cierta concepción de un cristianismo liberal y fue \\
un firme partidario del decreto de libertad de imprenta. Fue uno de \\
los firmantes de la Constitución y, ante la reacción antiliberal de 1814, \\
optó por una postura más reaccionaria, claramente populista. Murió \\
en Cádiz en Vl-1823, a la edad de 59 años. Archivo del Congreso de \\
los Diputados, Serie de Documentación Electoral, 1, núm. 6; Suárez \\
1982: 30; Gil Novales (dir.) 1991: 642; García León 2006: 515-7; \\
Menéndez Pelayo 1992, II: 720.
\end{tabular}

\begin{tabular}{c} 
CÓRDOBA \\
\hline Diputados titulares
\end{tabular}

CAVELLO LÓPEZ, Marcos (La elección fue anulada): Oriundo de la ciudad de Córdoba (1751-1819). Su formación la realizó en colegios y centros de Córdoba y Sevilla. Se doctoró en Teología. Fue elegido diputado propietario por el procedimiento para las provincias libres de los franceses en diciembre de 1810 . No obstante, las Cortes anularon su elección antes de que llegara a formar parte de ellas. Archivo del Congreso de los Diputados, Serie de Documentación Electoral, 1, núm. 9; Cuenca Toribio 1986: 482-3.

HENAO, Juan Mạ: En el Diario de Sesiones del Congreso aparece como Presbítero -Rector Beneficiado propio de San Andrés. Fue elegido diputado propietario por el procedimiento para las provincias libres de los franceses (21-V-1813). Archivo del Congreso de los Diputados, Serie de Documentación Electoral, 1, núm. 9.
JIMÉNEZ HOYO, Manuel (también figura como JIMÉNEZ o XIMÉNEZ): De este prebendado de la Santa Iglesia Catedral de Córdoba nos dice Valverde Madrid, que intervino en los debates que, sobre la cuestión de la abolición de la Inquisición se suscitaron en las Cortes. Era Doctor en Sagrada Teología. Elegido diputado propietario por el procedimiento para provincias libres de franceses en diciembre de 1810. Las Cortes anularon su elección el 12 de marzo de 1813. Archivo del Congreso de los Diputados, Serie de Documentación Electoral, 1, núm. 9; Valverde Madrid 1990: 142.

NIETO FERNÁNDEZ, Juan: Doctor en Sagrada Teología, así como Presbítero, vicario y cura de La Carlota (Córdoba). Fue elegido diputado propietario por el procedimiento para las provincias libres de los franceses (6-XII-1812). Las Cortes anularon su elección tras haber formado parte de ellas durante dos meses y trece días. Posteriormente, en nuevos comicios volvió a ser elegido. Fue dado de baja el 12-I-1813. Archivo del Congreso de los Diputados, Serie de Documentación Electoral, 1, núm. 9.

RODRÍGUEZ PALOMEQUE, Manuel (La elección fue anulada): Provisor electo de la abadía de Baza. El 6-XII-1812 fue elegido diputado propietario por el procedimiento para las provincias libres de los franceses. Mas las Cortes anularon su elección antes de que llegara a formar parte de ellas. Archivo del Congreso de los Diputados, Serie de Documentación Electoral, 1, núm. 9.

TORRE MARTINIANO, Juan de la: Catedrático de Teología. En los comicios del 6-XII-1812 fue elegido diputado propietario por el procedimiento para provincias libres de los franceses. Sin embargo, no llegó a Cádiz hasta el 6-I-1813, fecha en la que jura el cargo. Las Cortes anularon su elección tras haber formado parte de ellas durante dos meses y trece días. Muy cercano a un liberalismo moderado, tuvo muy escasa participación y defendió la ratificación como diputado a Cortes de Jiménez Hoyo. Archivo del Congreso de los Diputados, Serie de Documentación Electoral, 1, núm. 9; García León 2006: 518.

\section{GRANADA}

Diputados titulares

ALCAYNA Y GUIRAO, Antonio (también figura como Alcaína): Nace en Villa de María el 27-I-1755. Estudió más tarde en el Seminario de Orihuela. Con posterioridad, ganó por oposición el curato de Vicar (Almería), y en 1791 obtuvo el de Cuevas de Vera, de la provincia almeriense. Según consta en las fuentes consultadas fue elegido diputado propietario el 17-XI-1810, por el procedimiento para las provincias ocupadas en parte de los franceses. Este cura párroco de Cuevas de Vera ocupó un escaño por el reino de Granada. Le ofrecieron los obispados de Mallorca y Seo de Urgel, que rechazó. A su regreso Fernando VII le nombró Chantre de la Catedral de Orihuela, donde murió el 25 de octubre de 1825 . Gallego y Burín 1990: 89; Quirós 1911; Archivo del Congreso de los Diputados, Serie de Documentación Electoral, 2, núm.1.

BEJARANO, Pedro Inocencio: Nació en Selaya (Santander) en 1750. Cursó Teología en la Universidad de Granada. Asimismo, fue catedrático de la Sagrada Escritura; canónigo del Sacromonte y de San Isidoro de Madrid. Las sedes en las que ejerció su obispado fueron Buenos Aires (Argentina) y Sigüenza (1801). Falleció en 1818. Asimismo, fue nombrado diputado propietario por el procedimiento para las provincias ocupadas en parte por los franceses. Cesó en el cargo el 20-IX-1813. Archivo del Congreso de los Diputados, Serie de Documentación Electoral, 2, núm. 1; Cuenca Toribio 1986: 474-475.

GARCÉS Y VARGA, Francisco (Varea en el Diario de Sesiones del Congreso): Presbítero y vocal de la Junta Superior, designado el 18XII-1810 diputado por el reino de Granada (procedimiento para las provincias ocupadas en parte por los franceses). Cesó en el cargo el 20-IX-1813. Archivo del Congreso de los Diputados, Serie de Documentación Electoral, 2, núm. 1.

GONZÁLEZ BRICEÑO, Nicolás: Según las fuentes consultadas, era doctoral de la catedral de Sevilla. Fue elegido diputado propietario por el procedimiento para las provincias libres de los franceses. Cesó en el cargo el 20-IX-1813. Archivo del Congreso de los Diputados, Serie de Documentación Electoral, 2, núm. 1. 
GONZÁLEZ LÓPEZ, Sebastián: Arcipreste del Sagrario de Málaga. En la elección de 1 de marzo de 1813 fue nombrado diputado propietario por el procedimiento para las provincias libres de los franceses. Cesó en el cargo el 20-IX-1813. Archivo del Congreso de los Diputados, Serie de Documentación Electoral, 2, núm. 1.

SALAS, Juan de: Presbítero, elegido diputado por el reino de Granada el 18-XII-1810, procedimiento para provincias ocupadas en parte por franceses. Su participación en debates fue escasa. Fue uno de los firmantes de la Constitución. Cesó en el cargo el 20-IX-1813. Archivo del Congreso de los Diputados, Serie de Documentación Electoral, 2, núm. 1.

\section{Diputados suplentes}

ROMERO, Mateo (La elección fue anulada): Presbítero cura del Paúl. El 1-III-1813 fue elegido diputado suplente por el procedimiento para las provincias libres de los franceses. A pesar de su designación, no llegó a formar parte de las Cortes. Archivo del Congreso de los Diputados, Serie de Documentación Electoral, 2, núm. 1.

SIMÓ Y ZURITA, Gabriel (La elección fue anulada): Cura párroco según los expedientes electorales. El 17-XI-1810 fue nombrado diputado suplente (procedimiento para las provincias ocupadas en parte por los franceses). No llegó a formar parte de las Cortes. Archivo del Congreso de los Diputados, Serie de Documentación Electoral, 2, núm. 1.

\section{JAÉN}

Diputados titulares

TAUSTE, Tomás: En el Archivo del Congreso de los Diputados aparece como presbítero y prior de San Juan de la Villa. Asimismo, fue elegido diputado propietario por el procedimiento para las provincias libres de los franceses, del 25-I-1813 al 20-IX-1813. Archivo del Congreso de los Diputados, Serie de Documentación Electoral, 2, núm. 4.

SEVILLA

Diputados titulares

ALAJA, Francisco Basilio: Cura de Écija (Sevilla). El 25-V-1813 fue elegido diputado propietario por el procedimiento para las provincias libres de los franceses, concluyendo su mandato el 20-IX-1813. Archivo del Congreso de los Diputados, Serie de Documentación Electoral, 2, núm. 4.

CALDERÓN Y SARRIÁ, Antonio (La elección fue anulada): Desarrollaba el cargo de lectoral de la catedral de Málaga cuando fue elegido (por el procedimiento de las provincias libres de los franceses) por Sevilla. Al mes y medio, el acta se anuló. Archivo del Congreso de los Diputados, Serie de Documentación Electoral, 2, núm.17.

FREIRE, Juan José (también aparece como Freyre): Beneficiado de Carmona. El 26-VI-1813 fue elegido diputado propietario por el procedimiento para las provincias libres de los franceses. No tuvo ninguna participación activa. Archivo del Congreso de los Diputados, Serie de Documentación Electoral, 2, núm.17; García León 2006: 319.

MAESTRE Y FONS DE MONSALVE, Nicolás (La elección fue anulada): Nació en Sevilla en 1766. Inició sus estudios en el Colegio de Santo Tomás, graduándose en Teología en 1788 y doctorándose en 1790. Desempeño varias cátedras en la Universidad Hispalense y fue Canónico Lectoral de la Catedral de Sevilla. En 1831 fue elegido académico de la Historia y posteriormente visitador de monjas. Con respecto a este cargo «publicó unas circulares relativas a la ocupación de los bienes de las religiosas, por lo que se le condenó a destierro, si bien no llegó a cumplirlo por haberle sido perdonado. Fue juez auditor honorario del Tribunal de la Rota y subdelegado castrense, caballero de la orden de Carlos III, en 1828; individuo del Consejo de Su Majestad, gobernador del arzobispado de Sevilla (1836-40), y obispo electo de Tarazona. Entre sus obras se conserva impreso un Elogio fúnebre de la Reina Dọ María Josefa Amalia de Sajonia, pronunciado en la Iglesia de Nuestra Señora Regina Angelorum, en 1829». Elegido diputado suplente para las provincias libres de los franceses, el 13-I-1813. Sin embargo, al detectarse algunas anomalías se anuló la elección. Falleció en 1841. Archivo del Congreso de los Diputados, Serie de Documentación Electoral, 2, núm. 17.
MORENO Y GARINO, Agustín: Canónigo de la catedral de Sevilla, fue designado para representar a la provincia. Según las fuentes consultadas en el Archivo del Congreso de los Diputados, al advertirse diversas anomalías en la elección, el acta fue anulada. Sin embargo, para García León, "fue elegido el día 4 de mayo de 1813 , por diecinueve votos de los veintiocho electores [...] Se le otorgó poder el mismo día de su elección, siendo aprobado por las Cortes, en sesión pública, el día de julio de 1813, jurando y tomando posesión en la sesión del día 23 de julio, aunque tuvo ciertas dificultades para ser admitido como diputado. Debió de ser de pensamiento absolutista ya que, durante el Trienio, fue desterrado a Jerez de la Frontera, por anticonstitucional, el 18 de abril de 1821». García León 2006: 416; Archivo del Congreso de los Diputados, Serie de Documentación Electoral, 2, núm.17.

PRIETO, Pedro Manuel (La elección fue anulada): Nació en Écija (Sevilla), en el seno de una familia acomodada. Se doctoró en Sagrada Teología (1770) y llegó al grado de magistral de la Catedral de Sevilla. Escribió un tratado teológico titulado Singulare de scripturis Sacris opusculum, En el Diario de Sesiones del Congreso aparece su elección como diputado propietario de la división administrativa de Sevilla, el 13-I-1813. Al poco tiempo, las Cortes anularon esta designación. Falleció en 1822. Archivo del Congreso de los Diputados, Serie de Documentación Electoral, 2, núm.17.

SAAVEDRA SANGRONIS, Francisco de: Nació en Sevilla el 4-X1746, en el seno de una familia acomodada. Se graduó en Teología en la Universidad de Granada. Fue miembro del primer consejo de la Regencia. Fue ministro de Hacienda (9-XI-1797-6-IX-1798); ministro de Estado interino (28-III-1798-13-VIII-1798); ministro de Estado (6-IX-1798-II-1799); ministro de Hacienda (13-X-180830-X-1909) y ministro de Estado (1a Reg. 30-X-1809-31-I-1810). Además fue elegido diputado propietario por el procediendo para las provincias ocupadas en parte por los franceses. Renuncia al cargo por problemas de salud siendo sustituido por Juan Miguel Páez de la Cadena. Falleció en Sevilla el 25-XI-1819. Archivo del Congreso de los Diputados, Serie de Documentación Electoral, 2, núm.17; Moreno Alonso 1992: passim.; Cuenca Toribio y Miranda García 1998: 790-793.

SÁNCHEZ, Celestino (La elección fue anulada): En las elecciones de enero de 1813 fue designado el cura beneficiado propio de San Isidoro para representar a la provincia. Sin embargo, las Cortes anularon el acta. Archivo del Congreso de los Diputados, Serie de Documentación Electoral, 2, núm.17.

Diputados suplentes

BAENA, Pedro (La elección fue anulada): En los comicios del 13 de enero de 1813 fue designado este vicario general de Estepa para representar a su provincia de las Cortes de Cádiz. A los pocos días el acta fue anulada. Archivo del Congreso de los Diputados, Serie de Documentación Electoral, 2, núm.17.

RODRÍGUEZ DE BÁRCENA, Francisco de Sales: Nació en Sevilla. Inició sus estudios en el colegio de Santo Tomás. Perteneció a la Real Academia de Buenas Letras, así como a la Real Sociedad Médica Hispalense, en concepto de socio teólogo de erudición, consultor y revisor. Miembro del primer Consejo de Regencia. En las elecciones de 20-IX-1810 fue elegido diputado suplente por Sevilla, mostrando tanto celo en el desempeño de sus funciones que el rey, una vez repuesto en el trono, le recompensó en 1815 concediéndole una canonjía en la iglesia catedral de Sevilla. Fue corresponsal de EI Filósofo Rancio. "Una de las figuras más caracterizadas del sector más realista y tradicional, fue uno de los firmantes de la Constitución, aunque, evidentemente, no fue muy popular entre los elementos liberales, siendo insultado en varias ocasiones al salir de las sesiones de las Cortes». García León 2006: 479; Archivo del Congreso de los Diputados, Serie de Documentación Electoral, 2, núm.17; Archivo del Congreso de los Diputados, Serie General de Expedientes, legajo 124, núm. 23. 


\section{FUENTES PRIMARIAS}

Archivo del Congreso de los Diputados, Serie de Documentación Electoral, 1, núm. 6.

Archivo del Congreso de los Diputados, Serie General de Expedientes, legajo 124, núm. 23.

Diario de Sesiones a Cortes, legislatura de 1813, VII.

Diario de Sesiones a Cortes, legislatura de 1813, VIII.

Diarios de Sesiones a Cortes, 9 de octubre de 1813.

Diario de Sesiones a Cortes, de 30 de octubre de 1813.

Diario de Sesiones a Cortes, de 27 de marzo de 1814.

Diario de Sesiones a Cortes, de 9 de abril de 1814.

Constitución Política de la Monarquía Española de 19 de marzo de 1812. Grafía original de la época. http://hc.rediris.es/01/ Constituciones/constituc2.html [febrero 2013]. También se pueden consultar en: Diario de Sesiones ordinarias y Secretas: http://www.congreso.es/portal/page/portal/Congreso/Congreso/ Hist_Normas/200/H1812_3 [junio 2016]. Constitución de 1812 http://www.congreso.es/portal/page/portal/Congreso/Congreso/ Hist_Normas/ConstEsp1812_1978/Const1812 [junio 2016].

\section{BibLIOGRAFÍA}

Artola, M. (ed.) 1991. "Las Cortes de Cádiz». Ayer 1.

Caballero Mesa, F. 1991. La política andaluza en las Cortes de Cádiz. Málaga: Librería Ágora.

Capitán Díaz, A. 1978. Los Catecismos Políticos en España, 1808-1820. Un intento de educación política del pueblo. Granada: Caja General de Ahorros.

Capitán Díaz, A. 1991. Historia de la educación en España, vol. I. Madrid: Dykinson.

Comence, R. 1909. Antología de las Cortes de Cádiz. Madrid: Taurus.

Cuenca Toribio, J. M. 1973. Estudios sobre la Sevilla liberal (18121814). Sevilla: Publicaciones de la Universidad.

Cuenca Toribio, J. M. 1978. Aproximación a la historia de la Iglesia contemporánea en España. Madrid: Ediciones Rialp.

Cuenca Toribio, J. M. 1986. Sociología del episcopado español e Hispanoamericano (1789-1985). Madrid: Pegaso.

Cuenca Toribio, J. M. y Miranda García. S. 1998. El poder y sus hombres. ¿Por quiénes hemos sido gobernados los españoles? (1705-1998). Madrid: Actas.

Fernández Martín, M. 1885. Congreso de los Diputados. Comisión de gobierno interior. Madrid: Imprenta de los hijos J. A. García.

Gallego y Burín, A. 1990. Granada en la Guerra de la Independencia: Granada: Universidad de Granada.

García León, J. Ma 2006. Los diputados doceañistas. Una aproximación al estudio de los diputados de las Cortes Generales y Extraordinarias (1810-1813): Cádiz: Ayuntamiento de Cádiz.

Gil Novales, A. (dir.) 1991. Diccionario biográfico del Trienio Libera (DBTL): Madrid.

Guibourg, R. 2011. "Prefacio», en Mendonca, D. (ed). Compendio de una teoría analítica del Derecho. Alchourrón y Bulygin en sus textos. Buenos Aires: Marcial Pons.

Hera, A. de la 2008. "Los orígenes de la Confesionalidad y de la Libertad religiosa en el Derecho constitucional español». Anuario de Derecho Eclesiástico del Estado XXIV: 87-118.

Lafuente, M. 1882. Historia General de España. Vol. VI Desde los tiempos primitivos hasta la muerte de Fernando VII. Barcelona: Montaner y Simón.

López, R. J. 2011. «Hablar a la imaginación. Las ceremonias de proclamación y jura de la Constitución de 1812 en el noroeste peninsular». Obradoiro de Historia Moderna 20: 141-173.

Lorente, M. 1995. «El juramento constitucional». Anuario de Historia del Derecho Español 65: 585-632.
Martínez Blanco, A. 1994. La enseñanza de la religión en los centros docentes (a la luz de la Constitución y del acuerdo con la Santa Sede). Murcia: Secretariado de publicaciones Universidad de Murcia.

Menéndez Pelayo, M. 1992. Historia de los heterodoxos españoles, II. Madrid: CSIC (ed. Facs.).

Morán Orti, M. 1994. Revolución y reforma religiosa en las Cortes de Cádiz. Madrid: Actas.

Moreno Alonso, M. (ed.) 1992. Memorias inéditas de un ministro ilustrado. Sevilla: Castillejo.

Moreno Fernández, R. 2009. El personal del banco de España: desde su origen en el siglo XVIII hasta fin del siglo XIX, vol. I: Banco de San Carlos. Estudios de historia económica 54. Madrid: Banco de España.

Muñoz Pérez, J. 1987. "Los catecismos políticos: de la Ilustración al primer liberalismo español, 1808-1822». Gades, 16: 191-218.

Pérez Garzón, J. S. 2009. «El Estado, creador de Nación: los significados de Bayona y Cádiz», en Cuenca Toribio, J. M. (ed.), Ramos Rovi, M.a J. y Ventura Rojas, J. M. (coord.). Andalucía en la Guerra de la independencia (1808-1814): 141-160. Córdoba: Servicio de Publicaciones.

Pérez Vilariño, J. 1973. Inquisición y constitución en España. Madrid: Biblioteca Promoción del Pueblo. Serie P. núm. 65.

Puelles Benítez, M. 1991. «Del Despotismo llustrado a las Cortes de Cádiz: textos y documentos», en Capitán Díaz, A. 1991. Historia de la educación en España, vol. I: 333-335. Madrid: Dykinson.

Quirós, P. 1911. "Biografía del doctor D. Antonio Alcayna y Guirao». Revista de la Sociedad de Estudios Almerienses II: 33-52.

Ramos Rovi, M. a J. y Ventura Rojas, J. M. 2009. «Perfiles prosopográficos de los diputados por Andalucía en las Cortes de Cádiz», en Diego, $\mathrm{E}$, de (dir.) y Martínez Sanz, J. L. (coord.). El comienzo de la guerra de la Independencia. Madrid: ed. Actas.

Ramos Santana, A. 2004. La ilusión constitucional: pueblo, patria, nación. Cádiz: Universidad de Cádiz.

Revuelta González, M. 1973. Política religiosa de los liberales en el siglo XIX. El Trienio Constitucional. Madrid: CSIC. Escuela de Historia Moderna.

Revuelta González, M. 2005. La Iglesia española en el siglo xIX: desafíos y respuestas. Madrid: Universidad Pontificia de Comillas.

Rodríguez López-Brea, C. 2002. «¿Fue anticonstitucional el clero español? Un tópico a debate». Pasado y Memoria. Revista de Historia contemporánea 1: 237-252. http://publicaciones.ua.es/ filespubli/pdf/15793311RD17787467.pdf [consultado en junio 2016].

Sánchez Agesta, L. 1989. "Introducción», en Argüelles, A. Discurso preliminar a la Constitución de 1812: 9-63. Madrid: Centro de Estudios Constitucionales.

Sanchis Vidal, A. 2009. «La educación pública y católica: del afrancesamiento a Cádiz», en Cuenca Toribio, J. M. (ed.), Ramos Rovi, M.a J. y Ventura Rojas, J. M. (coord.). Andalucía en la Guerra de la independencia (1808-1814): 397-414. Córdoba: Servicio de Publicaciones.

Sanchis Vidal, A. y Ramos Rovi, M. a J. 2012. "La libertad de imprenta: un maridaje difícil entre Trento y Cádiz», en Repeto García, D. (coord.). Las Cortes de Cádiz y la historia parlamentaria: Cádiz: Servicio de Publicaciones de la Universidad de Cádiz.

Solis, R. 2000. El Cádiz de las Cortes. La vida en la ciudad en los años de 1810 a 1813. Madrid: Sílex.

Souto Paz, J. A. 2003. Comunidad política y libertad de creencias. Barcelona: Marcial Pons.

Suárez, F. 1982. Las Cortes de Cádiz. Madrid: Rialp.

Tomás y Valiente, F. 1977. «Notas para una nueva historia del constitucionalismo español». Sistema. Revista de Ciencias Sociales 17-18.

Valverde Madrid, J. 1990. "Los diputados cordobeses y granadinos en las Cortes de Cádiz de 1812». Boletín de la Real Academia de Córdoba de Ciencias, Bellas Letras y Nobles Artes 118: 141-149. 